21 patients undergoing chemotherapy for pancreatic cancer, and added an antibody that stimulates a protein called CD40 to their treatment regimen. CD40 is known to activate certain types of immune cell, including tumour-specific $\mathrm{T}$ cells. Tumours in four of the patients regressed.

The scientists repeated the treatment regime in mice genetically engineered to develop similar pancreatic cancers. About $30 \%$ of mouse tumours regressed, with holes appearing in the stroma.

Surprisingly, the immune cell responsible for killing tumour and stroma cells was not the T cell but the macrophage. Science 331, 1612-1616 (2011) For a longer story on this research, see go.nature. com/2ZNmhb

\section{NEUROSCIENCE}

\section{No sleep, better mood}

Sleep-deprived people are known to have stronger

reactions to negative experiences, but some patients with depression seem to

perk up with lack of sleep. To resolve this paradox, Matthew Walker at the University of California, Berkeley, and his team used functional magnetic resonance imaging to scan the brains of 14 people who hadn't slept for about 36 hours while presenting them with emotionally neutral and pleasant-looking images.

The volunteers rated a greater proportion of the images as 'pleasant' than did people who had maintained a normal sleep routine. The sleep-deprived individuals also showed increased activation in brain regions that mediate reward-driven behaviour, as well as greater connectivity between certain visual and emotional processing centres.

The results suggest that sleep deprivation can enhance reactivity to both positive and negative stimuli.

J. Neurosci. 31, 4466-4474 (2011)
BIOPHYSICS

\section{Tiny swimmers trapped by lasers}

Large, self-propelling microorganisms can be optically trapped with laser beams, a process previously achieved only for smaller motile cells such as sperm and Escherichia coli.

Gregor Thalhammer and his colleagues at Innsbruck Medical University in Austria used two opposing laser beams and a system involving a mirror, prism and lenses to capture a variety of organisms. These included protists such as dinoflagellates and Euglena gracilis, which measures, on average, 50 micrometres in length. The team's technique avoids creating damaging levels of heat. Euglena was held for 13 minutes without showing signs of heat stress. The method could be used to manipulate microbes for imaging, as well as in other experiments, the authors say. J. Opt. 13, 044024 (2011)

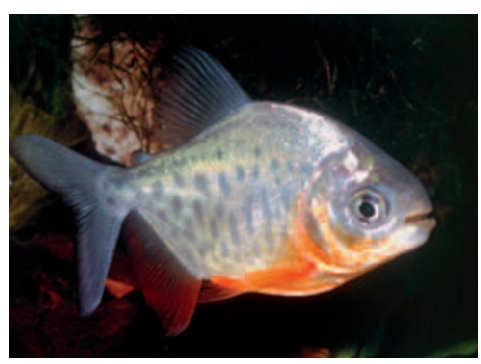

\section{ECOLOGY}

\section{Feasting fish scatter seeds}

Massive Amazonian characid fish can carry seeds kilometres across jungle flood plains, potentially making them one of the most important seed distributors in this habitat.

Jill Anderson, now at Duke University in Durham, North Carolina, and her colleagues radio-tracked 24 of the animals (Colossoma macropomum; pictured) during three flood seasons. They also monitored how long captive fish of this species retained consumed seeds.

COMMUNITY CHOICE

The most viewed papers in science

\title{
The roots of insulin production
}

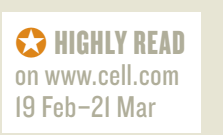

The pancreas harbours a small population of insulin-producing stem cells - cells that might one day be harnessed to replace damaged cells in people with diabetes.

Whether new insulin-producing $\beta$-cells in the adult pancreas develop from stem cells has been hotly debated. Simon Smukler and his colleagues at the University of Toronto in Ontario, Canada, now report the isolation of 'pancreas-derived multipotent precursor cells' from mouse and human tissue samples. These cells make insulin and can take on various cellular identities, including that of the $\beta$-cell. The authors traced the origin of the mouse precursor cells to the embryonic pancreas.

Transplantation of both mouse and human precursor cells into diabetic mice lowered blood sugar levels and reduced diabetes-associated weight loss.

Cell Stem Cell 8, 281-293 (2011)

The authors conclude that wild fish can probably carry seeds up to 5.5 kilometres one of the longest distances reported for fruit-eating animals - often to habitats where the seeds will germinate once the flood waters recede. However, overfishing has greatly depleted the numbers of larger C. macropomum, which carry seeds farther than their smaller counterparts, and may be threatening this mode of seed dispersal.

Proc. R. Soc. B doi:10.1098/ rspb.2011.0155 (2011)

For a longer story on this research see go.nature.com/ fv4zyd

\section{ARCHAEOLOGY}

\section{Early farmers caused floods}

Several hundred years before Europeans settled in North America, small Native American farming communities were already having a big impact on eastern flood plains - clearing the land and thus increasing erosion, runoff and flooding.

Gary Stinchcomb of Baylor University in Waco, Texas, and his colleagues dug deep into the banks of the Delaware River at a site in Pennsylvania looking for prehistoric changes in soil chemistry and sediment particle size, and for ancient plant material. They found increased sediment deposits from AD 1100-1600 - an indicator of elevated erosion - as well as signs that humans had cleared trees around rivers to farm corn. The erosion and flooding were made worse by the wet climate of the Little Ice Age in AD 1450-1530. European settlers later caused further ecological changes to the flood plains as a result of their various land-use practices. Geology 39, 363-366 (2011)

\section{CORRECTION \\ The highlight 'Copper makes for selectivity' (Nature 471, 413; 2011) stated that selectivity of $90 \%$ was achieved using organolithium reagents. In fact, this was achieved by using organolithium reagents in combination with copper-based catalysts.}

$\rightarrow$ NATURE.COM

For the latest research published by Naturevisit:

www.nature.com/latestresearch 